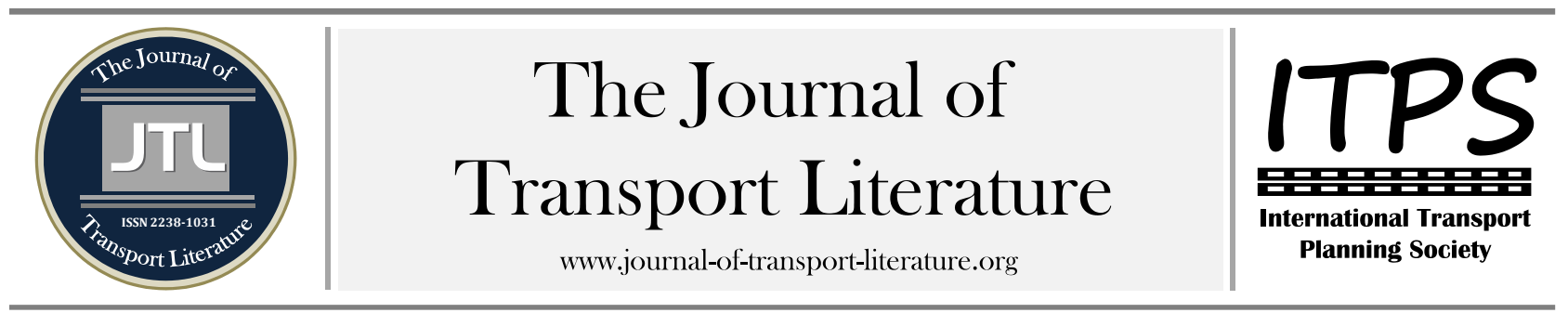

\title{
Effect of driver's personal characteristics on traffic accidents in Tabuk city in Saudi Arabia
}

Yazan Issa ${ }^{+}$

Civil Engineering Department, Fahd Bin Sultan University, Tabuk City, Saudi Arabia

\section{Article Info}

Keywords:

Traffic Safety,

Traffic Accidents,

Driver's Age,

Regulations,

Driving Experience

Submitted 1 Jun 2015; received in revised form 5 Jul 2015; accepted 12 Jul 2015.

Licensed under

Creative Commons

CC-BY 3.0 BR.

\begin{abstract}
Traffic accidents are a major problem in developing countries. Saudi Arabia is no exception to this worldwide dilemma. In Saudi Arabia a high incidence of road accidents has been recorded in the last several years due to various factors. The aim of this paper is to examine what factors contribute to road accidents in the study area; and to evaluate statistically the effect of certain driver's personal characteristics on road accidents. It is found that young drivers (less than 30 years) are involved in around $60 \%$ of the accidents and more than $80 \%$ of the accidents related to human factors. Contrary to expectation, higher driving experience and higher educational level involved in more accidents. The findings have shown the variables that had significant relationships with accidents in the city and those that did not have significance. Among the significant variables was age of the driver and his educational level. It appears that young drivers are highly participating in traffic accidents with less responsibility. The responsibility of accidents decreases with the high educated drivers. Conclusions were drawn as to deficiencies in driver training in Saudi Arabia and inadequacies of supervision by the law enforcement agents. The findings suggest a need for intensive efforts to be undertaken in Tabuk city to raise public awareness of road safety issues and to educate drivers in safe driving practices.
\end{abstract}

+ Corresponding author. Civil Engineering Department, Fahd Bin Sultan University, Tabuk, Saudi Arabia.

E-mail address: yissa@fbsu.edu.sa.

\section{Introduction}

The automobile is available for almost all households in Saudi Arabia in recent years due to the increase in per capita income. It should be mentioned that in Saudi Arabia, unlike other countries, women do not drive. For this reason, many families employ foreign chauffeurs. Women also rely heavily for transport on male relatives; there is therefore pressure on males to learn to drive and have a car at a very young age, in order to help in transporting their families to schools, malls or hospitals. All these factors have led to an increase in the usage of cars, resulting in more accidents. Road traffic accidents occur as a result of three factors, namely: road users, road environment and vehicles.

\section{Literature review}

A review of current literature was performed to understand as much as possible about accidents causes related to human factors. In year 2013, 91\% of all accidents involved human factors, 7\% accounted for vehicle factors, and 2\% were associated with road environments according to the Saudi traffic police report (Ministry of Interior, 2013). In another study, the number of deaths in Saudi Arabia due to traffic accidents in 2011 represents about $0.55 \%$ of the world deaths with 1.3 deaths for every 100 accidents (Al-Saif, 2012). The study of Boufous indicates that most of the traffic accidents related to driver's fatigue after midnight especially for young drivers (under 30 years), (Boufous, 2009). Another study in Greece indicates that foreign drivers participate more in traffic accidents, (Yannis, et al. 2007). A study presents that the difference in social and cultural concepts between countries increase the possibility of accident occurrence due to lack of communications (Factor, el all. 2007).

A study in Western Australia (Ryan et al., 1998) revealed that drivers aged under 25years were involved in 35\% of crashes, compared with only $3 \%$ for drivers 70 years and above. In Ireland, males are more often killed in road accidents than females (Lesley and Rooney, 1996). According to a report by Cerelli (1996), in the U. S., whereas male drivers accounted for $50.4 \%$ of all licensed drivers in 1996, they accounted for $62.8 \%$ of the total travel in the same year. Another study found that older drivers are at less risk of involvement in a road accident than young drivers, perhaps because they drive less frequently and for shorter distances, (ARAMCO, 1996). Thompson (1996) claimed that in the U. S, the automobile is number one cause of death among young people between 14 and 24 years. Road traffic accident involvement rates in the U. K. show that younger males are over represented in accidents (Dorn, 1992). 


\section{Study analysis}

The study aims to describe conditions of drivers in the study area (Tabuk City), and to identify causes of road traffic accidents based on a questionnaire distributed to drivers involved in traffic accidents. The questionnaire was divided into three parts, the first part: related to drivers certain personal demographics (such as: age, educational level, and driving experience). The second part: includes information about accidents (such as: location, time, cause, and responsibility). Finally, the third part: introduces certain questions to identify driver's knowledge, behavior, and recognition of road signs. The questionnaires were distributed in traffic police stations were accidents recorded and in hospitals to injured drivers in Tabuk City. Tabuk is the largest city of the northwestern region of Saudi Arabia. It has a population of about one million. And it is close to the Jordan-Saudi Arabia border.

The following equation can be used to estimate number of interviewed drivers who were involved in traffic accidents (since standard deviation is not known).

Where:

$$
\mathrm{N}=\mathrm{p}^{*} \mathrm{q}^{*}(\mathrm{Z} \alpha / 2 / \mathrm{d}) 2
$$

${ }^{*} p$ is the proportion of interviewed drivers with zero or $25 \%$ responsibility about accidents.

${ }^{*} \mathrm{q}$ is the proportion of interviewed drivers with $50,75,100 \%$ responsibility about accident:

To have the largest sample size (p) is considered as 0.5 . Confidence level is considered as $90 \%$ so $\mathrm{Z} \alpha / 2$ equal to 1.645 and permitted error (d) as \pm 0.1 , the sample size is 68 drivers. To avoid any missing data and to be more conservative this number is increased to about 90 drivers

\section{Results}

The analysis of the questionnaire is divided into three parts, the first part related to driver's personal characteristics, the second part goes through accident statistics, and the third part explains the main results from driver's traffic knowledge. It is clearly appeared that human factor is highly involved in traffic accident with the percentage of $82 \%$. About $81 \%$ of vehicles involved in the accidents are passenger cars. About $87 \%$ of drivers involved in traffic accidents understand traffic signs written in Arabic language, while 52\% only understand what is written in English language. $67 \%$ of drivers presented that the benefit from driving schools is little.

Young drivers (less than 30 years) are involved in about $60 \%$ of accidents while drivers more than 50 years old involved in only 4 percent of accidents. Drivers more than 5 years of driving experience are involved in about $65 \%$ of accidents, while drivers less than one year driving experience are involved in only $8 \%$ of accidents. Educational level of drivers involved in traffic accidents is presented in figure 1 below with about $47 \%$ of drivers having university level or more.

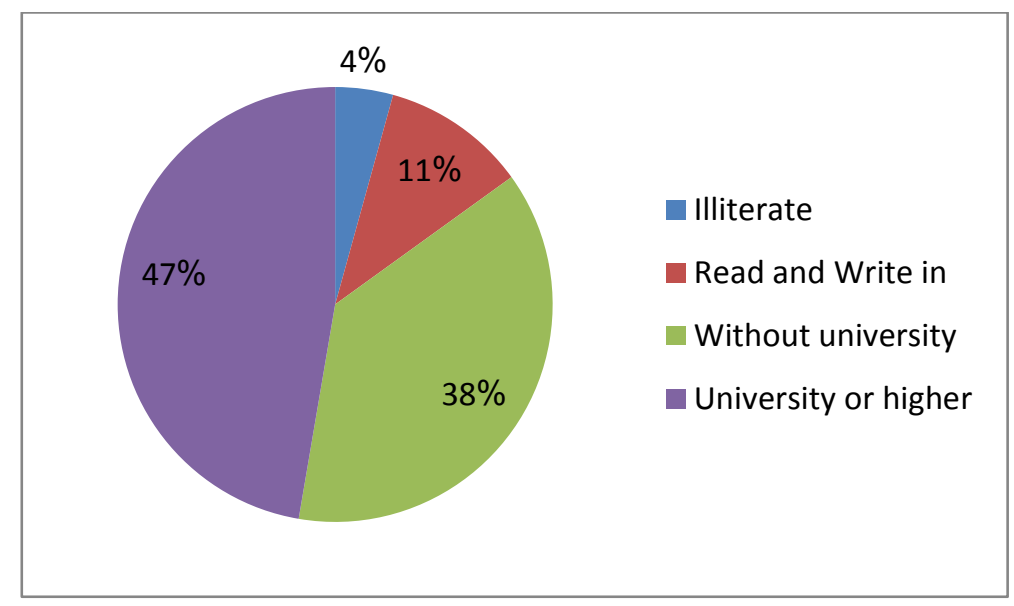

Figure 1 - Educational level of Drivers involved in Traffic Accidents 
The responsibility of drivers about traffic accidents is distributed as shown in table 1 below. It is assumed that drivers with zero or $25 \%$ are not responsible about the accident while those with 50,75 or $100 \%$ are responsible about the accident.

Table 1 - Driver responsibility about the accident

\begin{tabular}{|l|l|}
\hline Drivers responsibility about the accident & Percentage \\
\hline $100 \%$ & 23.4 \\
\hline $75 \%$ & 13.8 \\
\hline $50 \%$ & 24.5 \\
\hline $25 \%$ & 22.3 \\
\hline $0 \%$ & 16.0 \\
\hline Total & $100 \%$ \\
\hline
\end{tabular}

Roughly $81 \%$ of drivers answered correctly about the appropriate behavior when tire exploded. 95\% of drivers involved in traffic accidents recognize the maximum speed sign while only $41 \%$ recognize the yield sign. The results are also analyzed statistically using contingency tables and Chi-Square test between driver's personal characteristics and their responsibility about the accidents, a confidence level of $90 \%$ is adopted ( $\alpha=0.1$ ). The difference clearly appears in the two personal characteristics (age and educational level) as shown in table 2 and 3. Other characteristics (such as driving experience) do not represent a significant statistical difference.

Table 2 - The Relation between Drivers Age and their Responsibility about Accidents

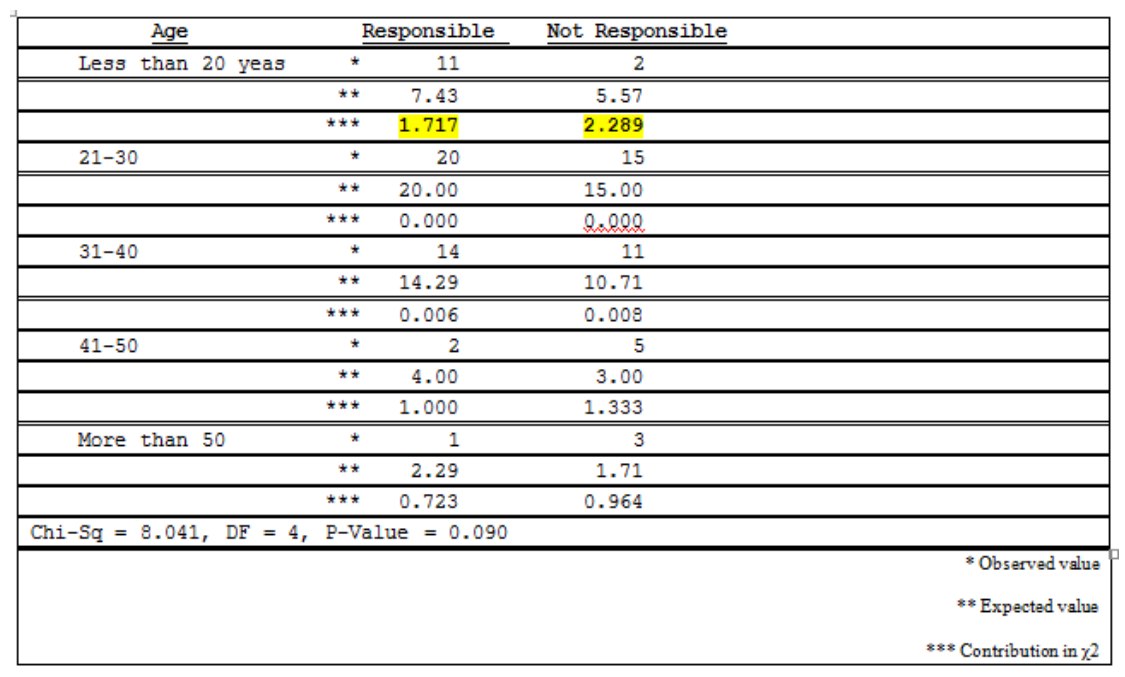

Table 3 - Relation between Drivers Educational Level and their Responsibility about Accidents

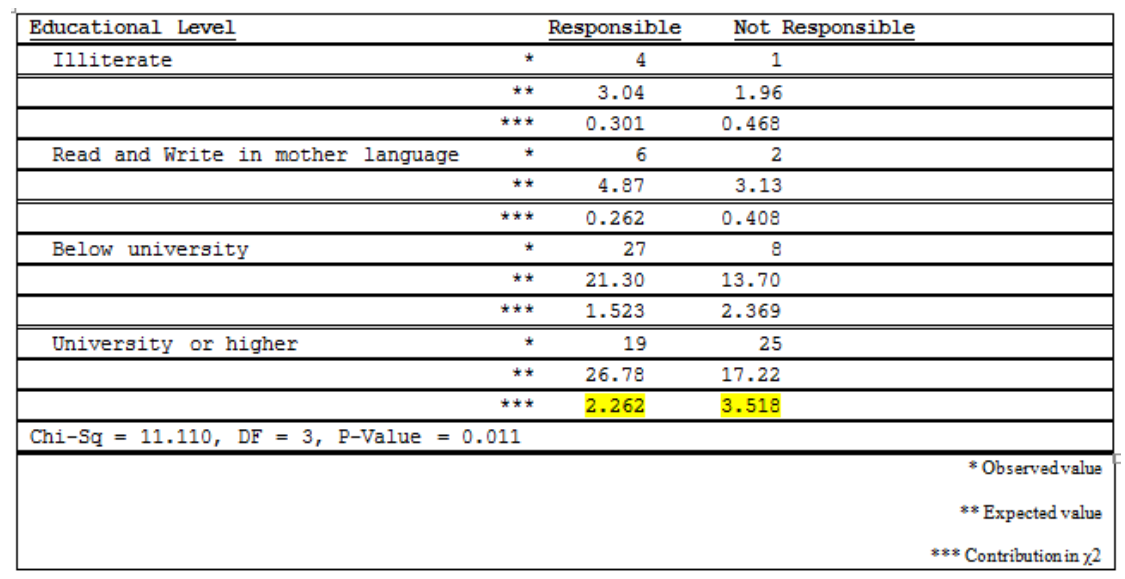


Since the P-Value in the above table is less than 0.1, this indicates that there is a statistical difference between driver's age and their responsibilities about accidents. The difference clearly appears in those with less than 20 years old where the responsible expected value is less than what is observed. This indicates that although young drivers highly participate in accidents, they are less responsible about it.

Since the P-Value in the above table is less than 0.1, this indicates that there is a statistical difference between driver's educational level and their responsibilities about accidents. The difference clearly appears in those drivers with university or higher where the responsible expected value is more than what is observed. This indicates that as educational level goes higher the responsibility of accidents decrease.

\section{Conclusion}

The findings have shown the variables that have significant relationships with accidents in the city and those that are not significant. Among the significant variables are age of the driver and his educational level. It appears that young drivers a re highly involved in traffic accidents but with less responsibility. The responsibility of accidents decreases with high educated drivers. The significant variables are those to which drivers, driving schools instructors, police and legislators need to pay particular attention. The low percentage of correct answers on some sign or general traffic culture questions indicate the low benefits achieved from driving schools, and the need to modify their programs and training courses.

It is also recommended to have intensive programs of awareness of traffic regulations and safety should be prepared and all information media should be utilized to increase the traffic awareness among people and drivers. Responsible agencies should also organize training programmers, induction courses and seminars for drivers where they would be taught the art of safe driving. Policy makers should promulgate a law that would restrict driving in Saudi Arabia to a certain age (18years old) and education level (school certificate). This is because these two variables were found to be significantly related with road accidents in Tabuk city. The curriculum of driving schools should include courses on the rules and regulations about driving, and observance of traffic regulations and other related matters about driving. 


\section{References}

Al-Saif. A, 2012. (Estimating the effect of traffic accidents in Arab Gulf Countries), Saudi Society for Traffic Safety, Dammam, Kingdom of Saudi Arabia.

ARAMCO (1996). Panorama, Special Traffic Issue, Saudi Aramco Loss Prevention Dept., Dhahran, Saudi Arabia.

Boufous, S., Williamson, A., 2009. Factors affecting the severity of work related traffic crashes in drivers receiving a worker's compensa tion claim. Accident Analysis and Prevention 41, 467-473.

Cerelli, E. (1996). Crash Data and Rates for Age-Sex Groups of Drivers, Report to the National Highway Traffic Safety Administration, U. S. Department of Transportation.

Dorn, L. (1992), "Individual and Group Differences in Driving Behaviour (Neuroticism, Gender, Age)", Ph. D. Thesis, Aston University, U. K.

Lesley, J. C. and Rooney, F. (1996). "Psychological factors in road traffic accidents Statistical evidence and a study of the effects of viewing an anti-speeding film", Irish Journal of Psychology, vol. 17, no. 1, pp 35-47.

Ministry of Interior, General Traffic Department, (Annual Statistical Report, 2013), Kingdom of Saudi Arabia.

Roni Factor, David Mahalel, Gad Yair, 2007. "The social accident: A theoretical model and research agenda for studying the influence of social and al characteristics on motor vehicle accidents". Accident Analysis and Prevention 39, 914-921.

Ryan, G. A., Legge, M. and Rosman, D. (1988), "Age-related changes in drivers' crash risk and crash type", in Accident Analysis and Prevention, vol. 30, no. 3, pp. 379-387.

Thompson, D. (1996), "Improving Teen Driving (Miracle in Crystal City)", The News and Observer, September 19, Raleigh, Carolina.

Yannis, G., Golias, J., apadimitriou, E. 2007, “Accident Risk of Foreign Drivers in Various Road Environments”, Journal of Sa fety Research 38. 471-480, Department of Transportation, Planning and Engineering, University of Athens, Athens, Greece, July 2007. 